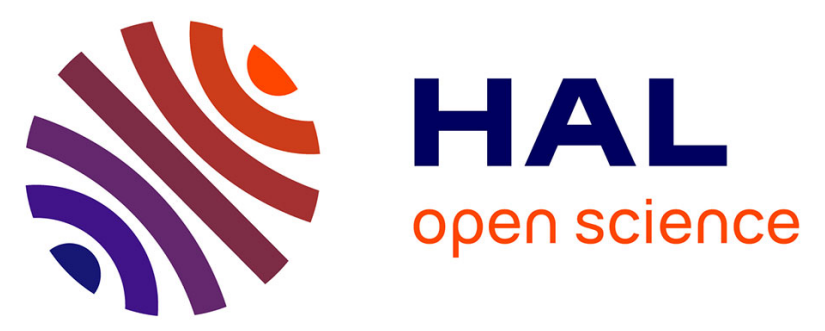

\title{
Modeling and optimization of a ball-burnished aluminum alloy flat surface with a crossed strategy based on response surface methodology
}

Hatem Hamdouni, Hassen Bouzaiene, Alex Montagne, Mustapha Nasri, Alain Iost

\section{To cite this version:}

Hatem Hamdouni, Hassen Bouzaiene, Alex Montagne, Mustapha Nasri, Alain Iost. Modeling and optimization of a ball-burnished aluminum alloy flat surface with a crossed strategy based on response surface methodology. International Journal of Advanced Manufacturing Technology, 2016, pp.1-14. 10.1007/s00170-016-8817-8 . hal-01313977

\section{HAL Id: hal-01313977 \\ https://hal.science/hal-01313977}

Submitted on 10 May 2016

HAL is a multi-disciplinary open access archive for the deposit and dissemination of scientific research documents, whether they are published or not. The documents may come from teaching and research institutions in France or abroad, or from public or private research centers.
L'archive ouverte pluridisciplinaire HAL, est destinée au dépôt et à la diffusion de documents scientifiques de niveau recherche, publiés ou non, émanant des établissements d'enseignement et de recherche français ou étrangers, des laboratoires publics ou privés. 


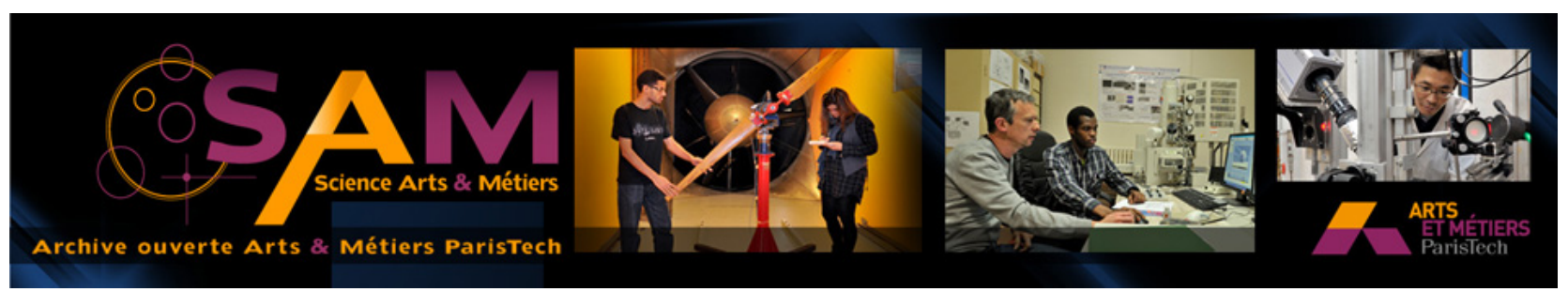

\section{Science Arts \& Métiers (SAM)}

is an open access repository that collects the work of Arts et Métiers ParisTech researchers and makes it freely available over the web where possible.

This is an author-deposited version published in: http://sam.ensam.eu

Handle ID: .http://hdl.handle.net/10985/10776

\section{To cite this version :}

Hatem HAMDOUNI, Hassen BOUZAIENE, Alex MONTAGNE, Mustapha NASRI, Alain IOST Modeling and optimization of a ball-burnished aluminum alloy flat surface with a crossed strategy based on response surface methodology - international journal of advanced manufacturing technology p.1-14 - 2016 


\title{
Modeling and optimization of a ball-burnished aluminum alloy flat surface with a crossed strategy based on response surface methodology
}

\author{
Hatem Amdouni $^{1} \cdot$ Hassen Bouzaiene $^{2} \cdot$ Alex Montagne $^{3} \cdot$ Mustapha Nasri $^{1} \cdot$ Alain Iost $^{3}$
}

\begin{abstract}
In this work, a new ball-burnishing strategy, in two crossed passes, was applied on the flat machined surface of 2017A-T451 aluminum alloy to investigate the influence of three classical ball-burnishing factors (burnishing speed $V_{b}$ in $\mathrm{mm} / \mathrm{min}$, depth of penetration $a_{b}$ in $\mu \mathrm{m}$ and lateral feed $f$ in $\mathrm{mm}$ ) on the treated surface integrity enhancement. Experimental work is based on the application of an experimental face-centered composite design (CCD) formed by three factors at three levels. The mathematical modeling of the average roughness $R a$, of the mean spacing of roughness profile irregularities $S m$ and of the surface hardness HIT of the treated surfaces was performed by the response surface methodology (RSM). Best ball-burnished surface integrity has been established by the application of optimal ballburnishing studied factors $\left(V_{b}=500 \mathrm{~mm} / \mathrm{min}, a_{b}=40 \mu \mathrm{m}\right.$, and $f=0.2 \mathrm{~mm}$ ). High surface quality is then characterized by a gain in average roughness $R a$ of $81 \%$, an enhancement in the mean spacing of profile irregularities $S m$ of $34 \%$ and an improvement in surface nano-hardness HIT of $17 \%$ when compared to the machined surface. Machined and ballburnished optimized surface characterization confirms surface finishing process power and contribution to surface integrity enhancement of treated flat surface.
\end{abstract}

Hatem Amdouni

hatemamdouni@gmail.com

1 Laboratoire de Photométrie, IPEIN, BP 62 Merazka, 8000 Nabeul, Tunisia

2 Research Unit in Solid Mechanics, Structures and Technological Development (99-UR11-46), ENSIT, Tunis, Tunisia

3 Arts et Métiers ParisTech, MSMP, 8 Boulevard Louis XIV, 59000 Lille, France
Keywords Ball-burnishing crossed strategy $\cdot$ Response surfaces methodology $\cdot$ Average roughness $\cdot$ Means spacing of profile irregularities $\cdot$ Nano-hardness $\cdot$ Aluminum alloy

\section{Introduction}

The 2XXX series aluminum alloys as 2017A-T451 are characterized by an excellent machinability and high mechanical strength. Then, this grade is used for various industrial applications forming a high strength structures, such as aircraft structures, machinery design, and military equipment. For against this, aluminum alloy has poor characteristics of formability, weldability, and corrosion resistance as shown in the web site (http://url.ie/z7ip). The enhancement of the corrosion resistance of metal alloys is usually the result of the surface integrity improvement by the application of the ballburnishing mechanical surface treatment process [1].

This technology is often applied for finishing functional machined surfaces of elastic-plastic and ductile materials. Ball-burnishing process was successfully applied for the inner surface integrity enhancement, of cylindrical part, of the 2014 aluminum alloys which are difficult-to-grind with conventional grinding [2]. W. Bouzid et al. have also shown that the ballburnishing surface treatment technology can replace grinding in the machining range of the piece [3]. Furthermore, ballburnishing process can be automated and coupled with the spherical grinding to finish the free-form surface plastic injection mold steel PDS5 on a CNC machining center [4].

Revankar et al. have shown that with the application of ball-burnishing optimized factors, we can achieve a great improvement in the surface integrity of the hard and resistance titanium alloy (Ti-6Al-4 V) [5]. The latter was predicted by a gain of $77 \%$ in the surface roughness and $17 \%$ in the surface hardness as compared with the machined one. Furthermore, 
López de Lacalle et al. have successfully finished the heattreated steels, Inconel 718, by ball-burnishing process in the aim of the enhancement of the free-form parts surface integrity, previously obtained by milling [6].

This cold-working process consists by the means of a rigid body, such as a rigid ball or a roller, of deforming plastically the roughness profile micro-peaks by pushing them into the micro-valleys. The latter was obtained following the material tearing necessary for the functional surface machining of mechanical parts [7].

This phenomenon allows the elimination of the "jaggedness" or saw-tooth topography which represents the cutting marks of the machined surface to make it smooth and hard [8, 9]. The surface hardening is due to the formation of an incompatibility of plastic deformation between the surface and the material under layers. To establish equilibrium state between surface and the material under layers, a compressive residual stress is, then, formed to a depth of up to $1 \mathrm{~mm}$ in depth $[3,10$, 11]. Generally, the enhancement of the mechanical surface properties is the result of the surface integrity improvement by ball-burnishing process of treated surface $[1,2]$.

The nonlinearity of the mechanical properties of the treated surfaces by ball burnishing, such as surface roughness and micro-hardness which are the most studied, shows that the successful application of the surface finishing technology requires the study and the optimization of several factors related to this process $[12,13]$.

The method commonly used by researchers for the process mastery is the mathematical modeling with the design of experiments. In recent years, researchers have frequently used the Taguchi method $[14,15]$, the response surface methodology [2,17], and the fuzzy logic method [16] for the parameters optimization of ball-burnishing process.

By using the Taguchi's orthogonal array method, the optimal plane ball-burnishing parameters for plastic injection molding steel PDS5 on a machining center was established by Fang-Jung Shiou et al. [14]. In this research, the effect of four ball-burnishing parameters, namely the ball material, burnishing speed, burnishing force, and feed, on roughness flat surface enhancement were studied and optimized. Then, the optimal plane ball-burnishing parameters were a combination of a tungsten carbide ball, a burnishing speed of $200 \mathrm{~mm} / \mathrm{min}$, a burnishing force of $300 \mathrm{~N}$, and a feed of $40 \mu \mathrm{m}$. Therefore, a $93 \%$ of average roughness enhancement was established by using the optimal burnishing parameters for plane burnishing.

The Taguchi technique also was used to optimize and identify the effect of ball-burnishing factors, burnishing speed, burnishing feed, burnishing force, and number of passes on surface roughness, surface micro-hardness, enhancement ratio of surface roughness, and improvement ratio of surface microhardness of a brass alloy. The analysis of results shows that the burnishing force is the dominant effect on the treated surface integrity predicted by $39.87 \%$ enhancement for surface roughness and $42.85 \%$ for surface micro-hardness. In addition, the latter force betterment effect is followed successively by those of the burnishing feed, the burnishing speed, and the number of passes [15].

A fuzzy rule-based system was successfully used to predict the influence of ball-burnishing speed, feed, and depth on the turned surface roughness of a brass alloy. The method has achieved an accuracy of $95.4 \%$ to predict the burnished surface roughness [16].

The use of the response surface methodology RSM with the application of an experimental central composite design CCD provides a large amount of information on the modeling and optimization of ball-burnishing process $[2,20]$.

An optimization strategy based on the approach of the desirability function (DFA) following the use of response surface methodology (RSM) with the application of an experimental rotating central composite design (CCD) was used for the surface integrity optimization of ball-burnished aluminum alloy 7178 treated surface [17]. Then, ball-burnishing force, number of tool passes, feed and ball-burnishing speed were the optimized factors in this study. Ball-burnishing force and number of tool passes have had significant effects on the roughness improvement of the treated surface.

The most significant and studied factors by researchers for finishing flat surfaces by ball-burnishing are in order of interest, feed, rolling force or depth of penetration, and linear burnishing speed which are the necessary ones for scanning a surface [12].

In addition, response surface methodology RSM was used for mathematical modeling and optimization of ballburnishing flat surface roughness of the tool steel ASSAB XW-5. Then, the optimum ball-burnishing factors (penetration depth, feed, and linear burnishing speed) were established [18]. In the latter study, machined surface roughness was reduced from 4 to $0.27 \mu \mathrm{m}$ after ball-burnishing. By the same optimization technique, the same research team had successfully reduced total roughness Rtm to $0.72 \mu \mathrm{m}$ of milled flat surface of the 1045 AISI steel by applying a penetration depth of $12 \mu \mathrm{m}$ and lateral feed of $112 \mu \mathrm{m}$ [19].

As well, the response surface methodology and BoxBehnken experimental design techniques were applied to optimize and predict the influence of roller burnishing factors namely spindle speed, depth of penetration, and feed on the surface roughness and micro-hardness improvement of TA2 alloy. Optimum combination of roller burnishing factors have lead to a $63 \%$ gain in surface roughness and a $28 \%$ enhancement in surface micro-hardness when compared to premachined surfaces [20].

Generally, this cold mechanical flat surface treatment can be achieved in one pass following a zig/zag ball strategy [21]. But most ball-burnishing optimizations advocate the use of two or three passes for the flat surface finishing of elasticplastic material [2]. 
Table 1 Chemical composition of 2017A-T451 aluminum alloy
Chemical composition of 2017A-T451

\begin{tabular}{lllllllllll}
\hline Elements & $\mathrm{Al}$ & $\mathrm{Si}$ & $\mathrm{Fe}$ & $\mathrm{Cu}$ & $\mathrm{Mn}$ & $\mathrm{Mg}$ & $\mathrm{Cr}$ & $\mathrm{Zn}$ & $\mathrm{Zr}+\mathrm{Ti}$ & Others total \\
\hline Weight \% & Rest & 0.76 & 0.7 & 3.82 & 0.54 & 0.67 & 0.1 & 0.25 & 0.25 & 0.15 \\
\hline
\end{tabular}

Furthermore, Salahshoor and Guo have compared the effect of the application of two kinds of ball-burnishing strategies to finish the flat surfaces by ball-burnishing [1]. In this study, the authors have shown that the ball-burnishing strategies in two crossed passes have a great potential on the flat surface integrity enhancement when compared to that in two parallel and successive ones.

For these reasons, the aim of this research is the use of response surface methodology (RSM) with the application of an experimental face-centered composite design (CCD) to optimize the flat surface integrity of the aluminum alloy 2017A-T451 by the application of a two crossed passes ballburnishing strategy.

\section{Experimental work}

A plate of size $1290 \times 310 \times 10 \mathrm{~mm}$ of a $2017 \mathrm{~A}-\mathrm{T} 451$ aluminum alloy which chemical composition and mechanical characteristics are shown in Tables 1 and 2 was used. As shown in Fig. 1, the machining of $60 \times 40 \times 10 \mathrm{~mm}$ size sample and the surface treatment by ball burnishing, according to the parameters shown in Table 3 were performed on the same three axes $\mathrm{CNC}$ machining center SPINNER VC650. A ball-burnishing tool providing a rolling contact between the rigid ball of $14 \mathrm{~mm}$ of diameter and the flat machined surface was designed as shown in Fig. 1a, b.

Two and three-dimensional roughness plots of the machined and ball-burnished surfaces quality were carried out by measurement roughness parameters using the optical interferometric profilometer Veeco Wyko NT9300. The surface and sub-layer nano-hardness (HIT) measurements of machined and ball-burnished surfaces were conducted on an MTS XP nanoindenter in classic mode indentation in charge-discharge.

The latter has been performed with a XP MTS instrument (USA) mounted with a three-sided pyramid (Berkovich tip).
The tip area function has been calibrated using a reference material of known modulus (fused quartz, $E=72 \mathrm{GPa}$ ). Load-displacement curves have been analyzed using the Oliver and Pharr method [22]. The loading profile used was as follows: a first load at $500 \mathrm{mN}$ in $30 \mathrm{~s}$, then a dwelling time of $12 \mathrm{~s}$ to avoid creep effect during the unloading part and finally, an unloading part to $0 \mathrm{mN}$ in $30 \mathrm{~s}$.

\section{Face-centered composite design}

To investigate the influence of ball-burnishing factors changes on the improvement of the average roughness $R a$, the mean spacing of profile irregularities $S m$, and the nano-hardness $H I T$ of treated flat surfaces, a three-factor face-centered composite design was constructed (burnishing speed $V_{b}$ in $\mathrm{mm} /$ min, penetration depth $a_{b}$ in $\mu \mathrm{m}$ and the lateral feed $f$ in $\mathrm{mm}$ ) at three levels $(-1,0,1)$ as shown in Table 4.

In this work, the face-centered composite design was constructed by a simple factorial design formed by 8 ballburnishing tests listed from 1 to 8 to guarantee the validity of the first order model, 4 center point tests enumerated from 9 to 12 to guarantee the tests repeatability, and 6 star point tests listed from 13 to 18 to establish the model of second degree, the star points are at the center of each face of the factorial space $(\alpha= \pm 1)$ as shown in Fig. 2 and Table 5.

The experimental design was executed randomly to avoid systematic errors. Therefore, three levels were considered for each studied ball-burnishing factor. According to the face-centered composite design with three independent factors, 18 experimental tests were conducted with the combination of listed values in Table 4 . The standard order of applying different ball-burnishing tests is shown in Table 5 as for the product of the mechanical surface treatment it is shown in Fig. 3b. The experimental tests of 2017-T451 aluminum alloy flat surfaces are executed in two crossed passes by applying the ZIG/ZAG_SEUIL
Table 2 Mechanical properties of 2017A-T451 aluminum alloy

\begin{tabular}{lllll}
\hline $\begin{array}{l}\text { Rm-tensile } \\
\text { strength (MPa) }\end{array}$ & $\begin{array}{l}\mathrm{Rp}_{0.2} 0.2 \% \text { proof } \\
\text { strength }(\mathrm{MPa})\end{array}$ & $\begin{array}{l}\text { A-Min. elongation } \\
\text { at fracture }(\%)\end{array}$ & $\begin{array}{l}\text { Brinell hardness } \\
(\mathrm{HBW})\end{array}$ & $\begin{array}{l}\text { Young's } \\
\text { modulus (MPa) }\end{array}$ \\
\hline 427 & 272 & 12 & 105 & 72,500 \\
\hline
\end{tabular}


Fig. 1 Experimental setup: a ball-burnishing tool design: (1) body, (2) screw, (3) blocking screw, (4) principal ball $14 \mathrm{~mm}$ of diameter, and (5) five

intermediate balls $7 \mathrm{~mm}$ of diameter. b Ball-burnishing tool mounted on CNC Milling Collet Chuck (6). c Application of ballburnishing process, (7) CNC Vise Clamps and (8) sample
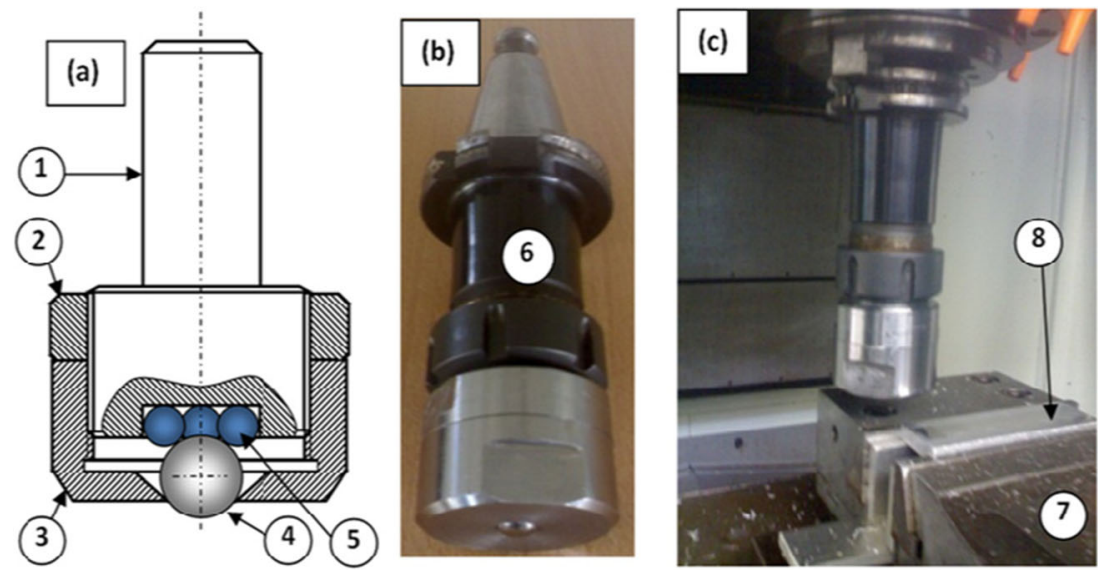

strategy. A first parallel ZIG/ZAG pass followed by a second perpendicular SEUIL pass relative to the machining direction $(X$-axis) as shown in Fig. 3a.

\section{Experimental results}

\subsection{Mathematical models}

The nonlinearity surface roughness and nano-hardness measured after ball-burnishing process application requires the search for nonlinear prediction models to find the best correlation between these mathematical models and experimental results [20].

In our study, the response surface methodology (RSM) is used to establish and model the functional relationships between quantitative factors $\left(x_{1}, x_{2}, \ldots \ldots, x_{k}\right)$ and the response surfaces of functions $Y(R a, S m$, and $H I T)$ as follows:

$Y=\mathrm{f}\left(x_{1}, x_{2}, \ldots \ldots, x_{\mathrm{k}}\right)+\mathrm{e}_{\mathrm{r}}$

In this case, the experimental errors are measured by the residual error term $\left(\mathrm{e}_{\mathrm{r}}\right)$. The response $Y$ was developed as quadratic polynomial under multiple regression forms as follows [23]:

$Y=\mathrm{b}_{0}+\sum \mathrm{b}_{\mathrm{i}} x_{i}+\sum \mathrm{b}_{\mathrm{ii}} x_{\mathrm{i}}^{2}+\sum \mathrm{b}_{\mathrm{ij}} x_{\mathrm{i}} x_{\mathrm{j}}+\mathrm{e}_{\mathrm{r}}$

When $b_{0}$, is the average response value, $b_{i}, b_{i i}$, and $b_{i j}$ are the regression coefficients. Then, the use of the ballburnishing speed $V_{b}$, the depth of penetration $a_{b}$, and lateral feed $f$ as three input factors of flat surface ballburnishing process allows the expression of each response $Y$ as follows:

$$
\begin{aligned}
Y= & \mathrm{b}_{0}+\mathrm{b}_{1} V_{b}+\mathrm{b}_{2} a_{b}+\mathrm{b}_{3} f+\mathrm{b}_{11} V_{b}^{2}+\mathrm{b}_{22} a_{b}^{2}+\mathrm{b}_{33} f^{2} \\
& +\mathrm{b}_{12} V_{b} a_{b}+\mathrm{b}_{13} V_{b} f+\mathrm{b}_{23} a_{b} f
\end{aligned}
$$

In response surface methodology (RSM), independent variable $Y$ is a surface represented by a properly adjusted mathematical model which best regression coefficients are listed in Table 6.

Model robustness is tested and improved by the analysis of variance (ANOVA), with quantifying the degree of process factors significance and by studying the different interactions existing between them as shown in Table 7 .

\begin{tabular}{|c|c|c|c|c|c|}
\hline \multicolumn{3}{|l|}{ Milling flat surface } & \multicolumn{3}{|c|}{ Ball-burnishing of machined surface } \\
\hline Parameter & Symbol & Quality & Parameter & Symbol & Quality \\
\hline Face milling cutter diameter & $D_{f}$ & $63 \mathrm{~mm}$ & Ball material & & Chromed 100Cr6 \\
\hline 3 carbide inserts & & TCMT 110204 & Ball diameter & $\varnothing_{\text {ball }}$ & $14 \mathrm{~mm}$ \\
\hline Spindle frequency & $N$ & $960 \mathrm{tr} / \mathrm{min}$ & Contact ball/surface & & Rolling \\
\hline Feed rate & $f_{m}$ & $384 \mathrm{~mm} / \mathrm{min}$ & Number of passes & $N_{P}$ & 2 \\
\hline Penetration of cut & $a_{f}$ & $0.4 \mathrm{~mm}$ & Burnishing speed & $V_{b}$ & $200-500-800 \mathrm{~mm} / \mathrm{min}$ \\
\hline Feed per tooth & $f_{z}$ & $0.08 \mathrm{~mm} /$ tooth & Depth of penetration & $a_{b}$ & $20-40-60 \mu \mathrm{m}$ \\
\hline Cutting speed & $V_{c}$ & $190 \mathrm{~m} / \mathrm{min}$ & Lateral feed & $f_{b}$ & $0.1-0.2-0.3 \mathrm{~mm}$ \\
\hline Lubricant & & None & Lubrifiant & & None \\
\hline
\end{tabular}

Table 3 Milling and ball-burnishing flat surface experimental parameters 
Table 4 Experimental levels of the ball-burnishing factors

\begin{tabular}{llllll}
\hline Factors & Notation & Code & \multicolumn{2}{l}{ Levels } \\
\cline { 5 - 7 } & & & $(-1)$ & $(0)$ & $(1)$ \\
\hline Burnishing speed $(\mathrm{mm} / \mathrm{min})$ & $V_{b}$ & $\mathrm{X} 1$ & 200 & 500 & 800 \\
Penetration depth $(\mu \mathrm{m})$ & $a_{b}$ & $\mathrm{X} 2$ & 20 & 40 & 60 \\
Lateral feed $(\mathrm{mm})$ & $f$ & $\mathrm{X} 3$ & 0.1 & 0.2 & 0.3 \\
\hline
\end{tabular}

The Pareto chart (Fig. 4) showing the standardized effects of the considered ball-burnishing factors, and their interactions, on the treated surfaces quality improvement as predicted by the average roughness $R a$, the mean spacing of the profile irregularities $S m$, and the nano-hardness HIT. These effects, shown on the chart, are statistically significant $(P<0.05)$ at a confidence level of $95 \%$.

However, for the nano-hardness response HIT, $\mathrm{b}_{3} f$ term with $P$ value $=0.6568>0.05$ is not statistically significant at a confidence level of $95 \%$ although the $\mathrm{b}_{23} a_{b} f$ term is statistically significant. Therefore the term $\mathrm{b}_{3} f$ is retained in the model to improve the lack-of-fit test (Table 6 and ANOVA Table 7).

As shown in Fig. 5, the principal ball-burnishing effect factors on surface integrity studied parameters of aluminum alloy 2017A-T451 are generally linear. They are, however, quadratic for the penetration depth $a_{b}$ and the lateral feed $f$ for the mean spacing of profile irregularities $S m$ as shown in Fig. 5b. For the average roughness $R a$, three interactions $\left(V_{b}-a_{b}\right),\left(V_{b}-f\right)$,

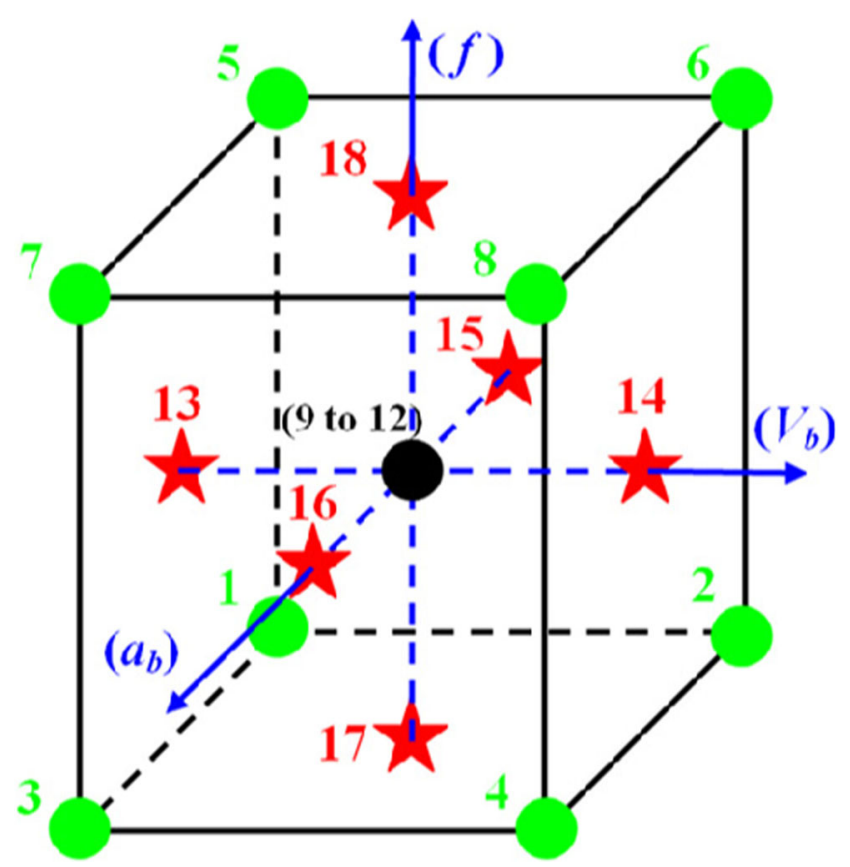

Fig. 2 Experimental face-centered composite design with three quantitative factors and $\left(a_{b}-f\right)$ are statistically significant at a confidence level of $95 \%$. The $\mathrm{b}_{12} V_{b} a_{b}$ term has a $P$ value $=0.0072<0.05$, the $\mathrm{b}_{13}$ $V_{b} f$ term has a $P$ value $=0.0190<0.05$ and $\mathrm{b}_{23} a_{b} f$ term has a $P<<10^{-4}<0.05$ as shown in Table 6 and Fig. 6 a. The latter is the strongest interaction that exists for the average roughness $R a$.

For the mean spacing of profile irregularities $S m$ only two interactions $\left(V_{b}-a_{b}\right)$ and $\left(a_{b}-f\right)$ are statistically significant. The $\mathrm{b}_{12} V_{b} a_{b}$ term has a $P$ value $=0.0015<0.05$ and the term $\mathrm{b}_{23} a_{b} f$ has a $P$ value $=0.0017<0.05$ as shown in Table 6 and Fig. $6 \mathrm{~b}$.

For the nano-hardness greatness, only two interactions, $\left(V_{b}-a_{b}\right)$ and $\left(a_{b}-f\right)$, are statistically significant. The $\mathrm{b}_{12}$ $V_{b} a_{b}$ term has a $P$ value $=0.0145<0.05$ and the $\mathrm{b}_{23} a_{b} f$ term has a $P$ value $=0.0540 \approx 0.05$ as shown in Table 6 and Fig. $6 \mathrm{c}$.

By referring to the statistical adjusted coefficient $R^{2}$, the three mathematical models developed in this study are, respectively, experimentally reliable of $90,65 \%$ for the average roughness $R a$, of $89.80 \%$ for the mean spacing of profile irregularities $\mathrm{Sm}$, and of $83.64 \%$ for the nano-hardness HIT as shown in Table 6.

In addition, the ANOVA table shows that the three mathematical models developed in this study of the three ballburnished surface integrity responses $(R a, S m$, and HIT) present a statistically significant relationship between variables in each model at a level confidence of $99 \%\left(P<10^{-4}\right)$. Furthermore, the lack-of-fit test confirms that the mathematical models developed out of the two responses $R a$ and $S m$ are suitable for the description of the observed experimental data $(P<0.05)$ at a confidence level of $95 \%$, whereas the nano-hardness HIT mathematical model has a $P$ value $=0.0984>0.05$ as shown in Table 7 .

The DW statistical test indicates that there is no serious autocorrelation between their residues (DW value $>1.4$ ). Normal probability plots for residual show that the error terms for all the three developed mathematical models are, in fact, normally distributed as shown in Fig. 7.

Finally, this statistical study of the ball-burnishing process of aluminum alloy 2017A-T451 flat surface by face-centered composite design allows us to mathematically model the three responses of surface integrity $(R a, S m$, and $H I T)$ according to the variation factors $\left(V_{b}, a_{b}\right.$, and $\left.f\right)$ as follows:

$$
\begin{aligned}
R_{a}= & 0.075+0.0279 V_{b}+0.0451 a_{b}+0.0381 f \\
& +0.024125 V_{b} a_{b}+0.020125 V_{b} f \\
& +0.053375 a_{b} f \\
S_{m}= & 12.2563-2.114 V_{b} \\
& +3.243 a_{b}-4.479 f-4.125 V_{b} a_{b} \\
& +7.83484 a_{b}^{2}-4.05 a_{b} f+4.21484 f^{2} \\
H I T= & 1.87002-0.05887 V_{b}+0.11562 a_{b}
\end{aligned}
$$

$$
+0.00665 f-0.0466 V_{b} a_{b}+0.03485 a_{b} f
$$


Table 5 Experimental design matrix and result of surface quality

\begin{tabular}{|c|c|c|c|c|c|c|c|c|c|c|}
\hline \multirow[t]{3}{*}{ Type } & \multirow[t]{3}{*}{ Standard order } & \multicolumn{6}{|c|}{ Factor level } & \multicolumn{3}{|c|}{ Surface quality } \\
\hline & & \multicolumn{3}{|c|}{ Coded } & \multicolumn{3}{|l|}{ Actual } & \multirow[b]{2}{*}{$R a(\mu \mathrm{m})$} & \multirow[b]{2}{*}{$S m(\mu \mathrm{m})$} & \multirow[b]{2}{*}{$H I T(\mathrm{GPa})$} \\
\hline & & $V_{b}$ & $a_{b}$ & $f$ & $V_{b}(\mathrm{~mm} / \mathrm{min})$ & $a b(\mu \mathrm{m})$ & $f(\mathrm{~mm})$ & & & \\
\hline \multirow[t]{8}{*}{ Factorial design } & 1 & -1 & -1 & -1 & 200 & 20 & 0.1 & 0.048 & 21.22 & 1.7808 \\
\hline & 2 & 1 & -1 & -1 & 800 & 20 & 0.1 & 0.042 & 24.76 & 1.805 \\
\hline & 3 & -1 & 1 & -1 & 200 & 60 & 0.1 & 0.015 & 42.52 & 2.076 \\
\hline & 4 & 1 & 1 & -1 & 800 & 60 & 0.1 & 0.04 & 32.51 & 1.8962 \\
\hline & 5 & -1 & -1 & 1 & 200 & 20 & 0.3 & 0.011 & 18.07 & 1.7705 \\
\hline & 6 & 1 & -1 & 1 & 800 & 20 & 0.3 & 0.02 & 21.89 & 1.6834 \\
\hline & 7 & -1 & 1 & 1 & 200 & 60 & 0.3 & 0.126 & 26.12 & 2.1875 \\
\hline & 8 & 1 & 1 & 1 & 800 & 60 & 0.3 & 0.297 & 10.49 & 1.9316 \\
\hline \multirow[t]{4}{*}{ Center point } & 9 & 0 & 0 & 0 & 500 & 40 & 0.2 & 0.069 & 12.52 & 1.8753 \\
\hline & 10 & 0 & 0 & 0 & 500 & 40 & 0.2 & 0.072 & 11.66 & 1.8397 \\
\hline & 11 & 0 & 0 & 0 & 500 & 40 & 0.2 & 0.065 & 12.9 & 1.8489 \\
\hline & 12 & 0 & 0 & 0 & 500 & 40 & 0.2 & 0.055 & 11.97 & 1.8214 \\
\hline \multirow[t]{6}{*}{ Start point } & 13 & -1 & 0 & 0 & 200 & 40 & 0.2 & 0.063 & 15.24 & 1.9179 \\
\hline & 14 & 1 & 0 & 0 & 800 & 40 & 0.2 & 0.143 & 12.38 & 1.8278 \\
\hline & 15 & 0 & -1 & 0 & 500 & 20 & 0.2 & 0.026 & 15.16 & 1.7859 \\
\hline & 16 & 0 & 1 & 0 & 500 & 60 & 0.2 & 0.12 & 21.89 & 1.8905 \\
\hline & 17 & 0 & 0 & -1 & 500 & 40 & 0.1 & 0.033 & 15.08 & 1.8352 \\
\hline & 18 & 0 & 0 & 1 & 500 & 40 & 0.3 & 0.105 & 14.73 & 1.8867 \\
\hline
\end{tabular}

Fig. 3 Ball-burnishing product: a ball-burnishing crossed strategy for the flat machined surface scanning and $\mathbf{b}$ application of experimental design and configuration of 18 ballburnishing tests
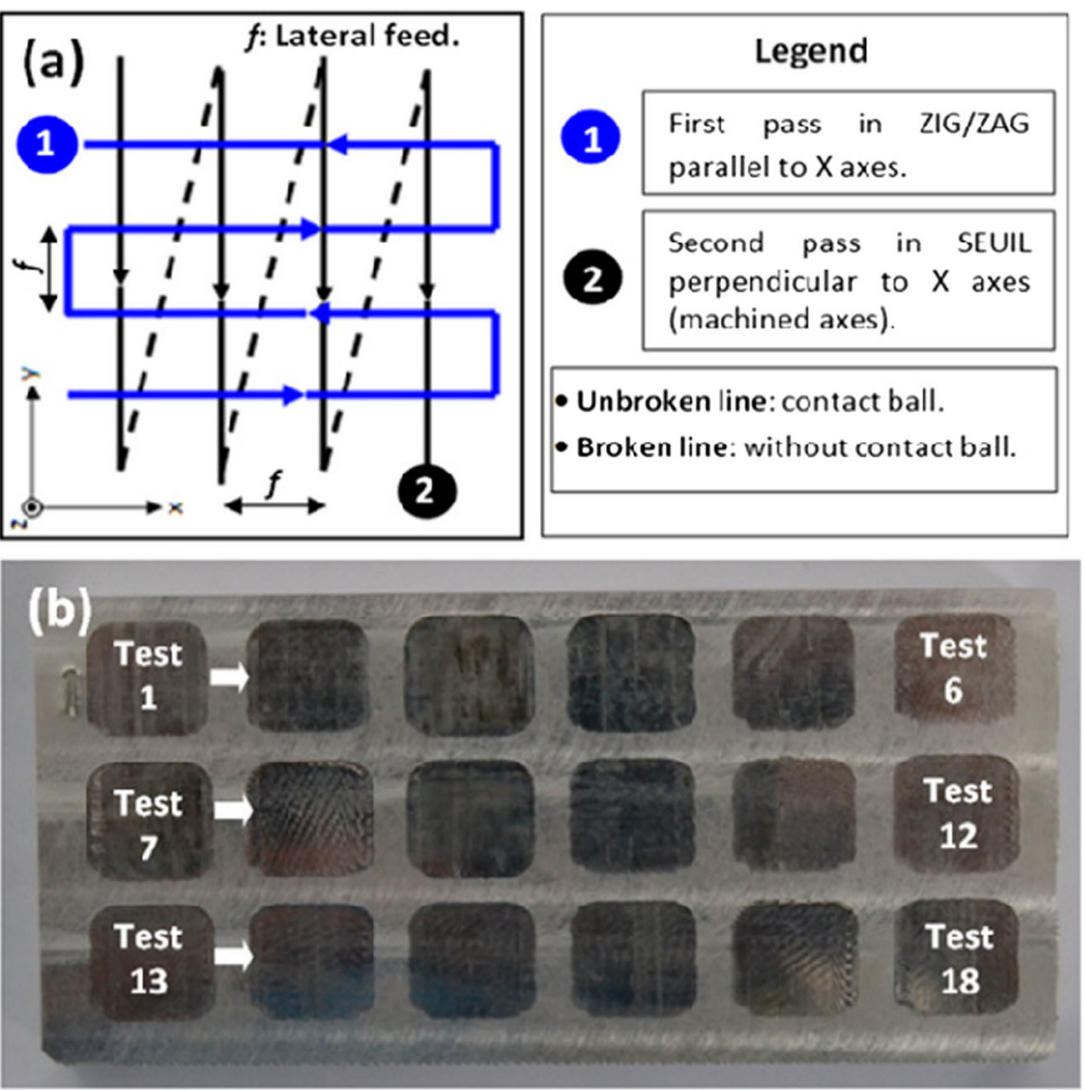
Table 6 Coefficients of regression models for ball-burnishing surface integrity

\begin{tabular}{|c|c|c|c|c|c|c|c|c|c|}
\hline \multirow[t]{2}{*}{ Coefficient } & \multicolumn{3}{|c|}{ Average roughness $(R a)$} & \multicolumn{3}{|c|}{ Mean spacing of profile irregularities $(\mathrm{Sm})$} & \multicolumn{3}{|c|}{ Nano-hardness $(H I T)$} \\
\hline & Est. & SE & $P$ value & Est. & SE & $P$ value & Est. & SE & $P$ value \\
\hline $\mathrm{b}_{0}$ & 0.075 & 0.00488469 & 0.0000 & 12.2563 & 1.0239 & 0.0000 & 1.87002 & 0.01088 & 0.0000 \\
\hline $\mathrm{b}_{1}$ & 0.0279 & 0.0065535 & 0.0013 & -2.114 & 0.849826 & 0.0321 & -0.05887 & 0.014597 & 0.0017 \\
\hline $\mathrm{b}_{2}$ & 0.0451 & 0.0065535 & 0.0000 & 3.243 & 0.849826 & 0.0034 & 0.11562 & 0.014597 & 0.0000 \\
\hline$b_{3}$ & 0.0381 & 0.0065535 & 0.0001 & -4.479 & 0.849826 & 0.0004 & 0.00665 & 0.014597 & 0.6568 \\
\hline \multicolumn{10}{|l|}{$b_{11}$} \\
\hline$b_{22}$ & & & & 7.83484 & 1.52633 & 0.0004 & & & \\
\hline$b_{33}$ & & & & 4.21484 & 1.52633 & 0.0201 & & & \\
\hline$b_{12}$ & 0.024125 & 0.00732704 & 0.0072 & -4.125 & 0.950135 & 0.0015 & -0.0466 & 0.01632 & 0.0145 \\
\hline$b_{13}$ & 0.020125 & 0.00732704 & 0.0190 & & & & & & \\
\hline $\mathrm{b}_{23}$ & 0.053375 & 0.00732704 & 0.0000 & -4.05 & 0.950135 & 0.0017 & 0.03485 & 0.01632 & 0.0540 \\
\hline$R^{2}$ & $93.9472 \%$ & & & $93.9979 \%$ & & & 88.4532 & & \\
\hline $\mathbf{R}_{\mathbf{a d j}}^{2}$ & $90.6457 \%$ & & & $89.7965 \%$ & & & 83.642 & & \\
\hline SE of est. & 0.020724 & & & 2.68739 & & & 0.0461599 & & \\
\hline
\end{tabular}

Est estimate, $S E$ standard error, SE of est. standard error of estimate

\subsection{Discussion}

\subsubsection{Ball-burnishing factor effects on average surfaces roughness $R a$}

The response surface $R a=\mathrm{f}\left(V_{b}, a_{b}\right)$ is the plot of Eq. (4) by keeping the level 0 of the lateral feed $f$. It represents the influence of the variation of both statically significant factors at a 95 and $99 \%$ confidence level, respectively, $V_{b}(P$ value $=0.0013<0.05)$ and $a_{b}\left(P<10^{-4}\right)$ as shown in Fig. $8 \mathrm{a}$ and Table 6 . The response surface plot shape, in this case, is a combined and simultaneous effect between the two linear effects of terms $\mathrm{b}_{1} V_{b}, \mathrm{~b}_{2} a_{b}$, and the effect of the existing interaction between $V_{b}$ and $a_{b}$ for the zero level of the lateral feed $f$.

The application of ball-burnishing strategy in two crossed passes, using a low burnishing speed and a low penetration depth, the point corresponding to levels $(-1,-1,0)$, allows us to have an average roughness $R a$ ranging between 0.018 and $0.036 \mu \mathrm{m}$. That is to say, a good surface state predicted by a gain in surface quality ranges from 86.66 to $93.33 \%$. For against the use of high ball-burnishing speed and a high penetration depth, the point corresponding to the levels $(1,1,0)$ allows us to have an average roughness $R a$ ranging between 0.162 and $0.18 \mu \mathrm{m}$. That is to say, a surface state predicted by a gain in average roughness ranges from 33.33 to $40 \%$.

For a given lateral feed, increasing the penetration depth causes increasing normal and tangential forces between the rolling ball and the treated surface. This fact provides the necessary mechanical energy for surface and subsurface defects and dislocations to migrate from a grain boundary to another until they emerge under the increase of the ballburnishing speed. This phenomenon, then, prevents the flow

Table 7 ANOVA for ball-burnishing surface integrity

\begin{tabular}{|c|c|c|c|c|c|c|c|c|c|}
\hline \multirow[t]{2}{*}{ Coefficient } & \multicolumn{3}{|c|}{ Average roughness $(R a)$} & \multicolumn{3}{|c|}{ Mean spacing of profile irregularities $(\mathrm{Sm})$} & \multicolumn{3}{|c|}{ Nano-hardness (HIT) } \\
\hline & $\mathrm{SS}$ & $D_{f}$ & $P$ value & SS & $D_{f}$ & $P$ value & SS & $D_{f}$ & $P$ value \\
\hline Model & 0.0733277 & 6 & 0.0000 & 1131.04 & 7 & 0.0000 & 0.195867 & 5 & 0.0000 \\
\hline Residual & 0.00472433 & 11 & & 72.2205 & 10 & & 0.0255688 & 12 & \\
\hline Lack-of-fit & 0.00455958 & 8 & 0.0401 & 71.2992 & 7 & 0.0077 & 0.0240575 & 9 & 0.0984 \\
\hline Pure error & 0.00016475 & 3 & & 0.921275 & 3 & & 0.00151133 & 3 & \\
\hline Total correction & 0.078052 & 17 & & 1203.26 & 17 & & 0.221436 & 17 & \\
\hline DW value & 1.88192 & & & 2.22513 & & & 1.67512 & & \\
\hline
\end{tabular}

$D W$ Durbin-Watson statistic, $S S$ sum of squares, $D_{f}$ degree of freedom 

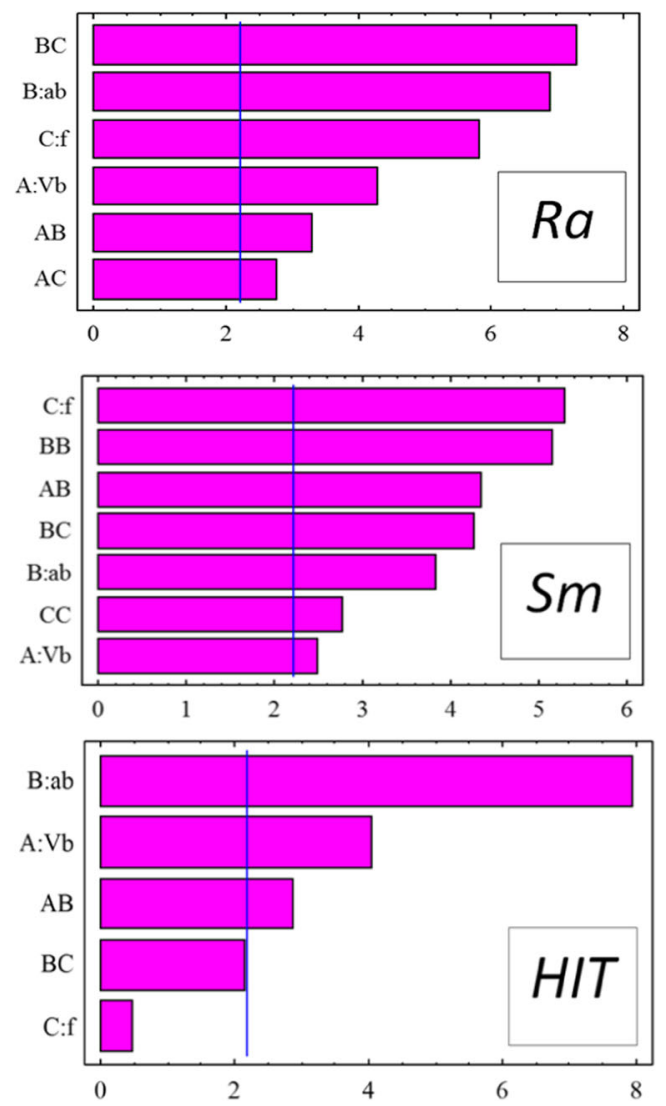

Fig. 4 Pareto chart of standardized effects for $(R a)$ average roughness, $(\mathrm{Sm})$ the mean spacing of profile irregularities, and (HIT) the nanohardness

of material and promotes the formation of surface cracks and the primer surface damage by chipping.

Figure $8 \mathrm{~b}$ shows the response surface $R a=\mathrm{f}\left(V_{b}, f\right)$ for a zero level fixing penetration depth of $40 \mu \mathrm{m}$. This plot shows the interaction effect of ball-burnishing speed $V_{b}$ and lateral feed $f$ statistically significant at $95 \%$ confidence level $(P$ value $=0.0001$ ).

The combination of low ball-burnishing speed with a low lateral feed for the given penetration depth allows a good surface quality predicted by an average roughness $R a$ ranging between 0.018 and $0.036 \mu \mathrm{m}$. That is to say, a gain in surface quality ranges from 86.66 to $93.33 \%$.

As against, poor quality surface $(0.144 \mu \mathrm{m} \leq R a \leq 0.162 \mu \mathrm{m})$ is produced by the combination of high ball-burnishing speed and high lateral feed. This worst surface quality is growing with the combined increase of the previous two ball-burnishing factors. This fact is a result of the existing interaction, $\mathrm{b}_{13} V_{b} f$ term, between the two factors in Fig. 6a, which is statistically significant $(P$ value $=0.0190)$ with a confidence level of $95 \%$ as shown in Table 6.

When using high ball-burnishing speed, the roughness peaks while being in the ball-to-surface contact area do not have the necessary time to be plastically deformed and be pushed in the initial roughness valley, but they will be
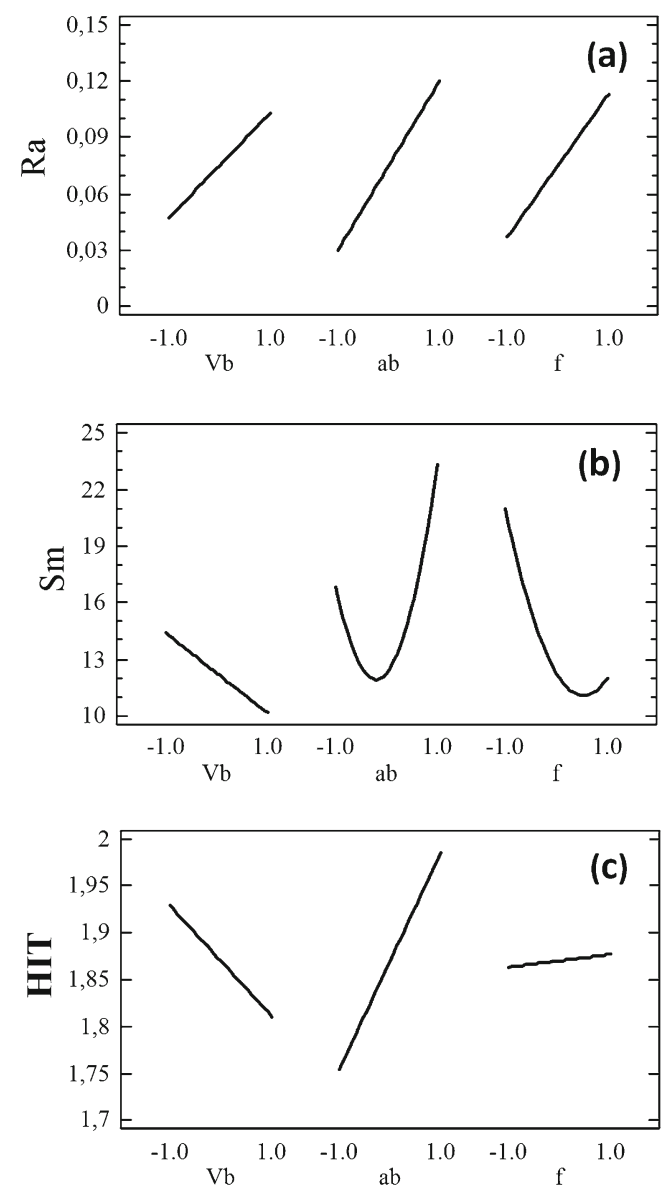

Fig. 5 Main ball-burnishing effect plots: a average roughness $R a$, b the mean spacing of profile irregularities $\mathrm{Sm}$, and $\mathbf{c}$ the micro-hardness HIT

repulsed at left and right from the ball-burnishing path in the direction of the ball-burnishing speed.

Then, the edge height of the formed track increases after each ball-burnishing pass, and leads to the increase of the roughness by damaging the treated surface. This phenomenon is aggravated by the augmentation of the number of passes and the lateral feed which is responsible of the decrease of the surface recovery rate.

In this case, this kind of surface degradation is related to the mechanical surface treatment morphology itself. That is to say, the nature of the ball-burnishing strategy is already used.

The response surface $R a=\mathrm{f}\left(a_{b}, f\right)$ (Fig. 8c) confirms by its shape the linear effect of the penetration depth $a_{b}$ and that of the lateral feed $f$ on the quality treated surfaces evolution for the ball-burnishing speed zero level $\left(V_{b}=500 \mathrm{~mm} / \mathrm{min}\right)$.

The best surface quality ranging between 0.018 and $0.036 \mu \mathrm{m}$ is obtained for the $(0,1,-1)$ level factors, then, it is worsened at $(0,1,1)$ levels. So, the increase in lateral feed $f$ and depth of penetration $a_{b}$ accelerates the deterioration of the surface quality for a given ball-burnishing speed. The surface destruction, in this case, is a combined effect of the two phenomena mentioned previously, of flaking caused by the increase on the penetration depth and that caused by the 

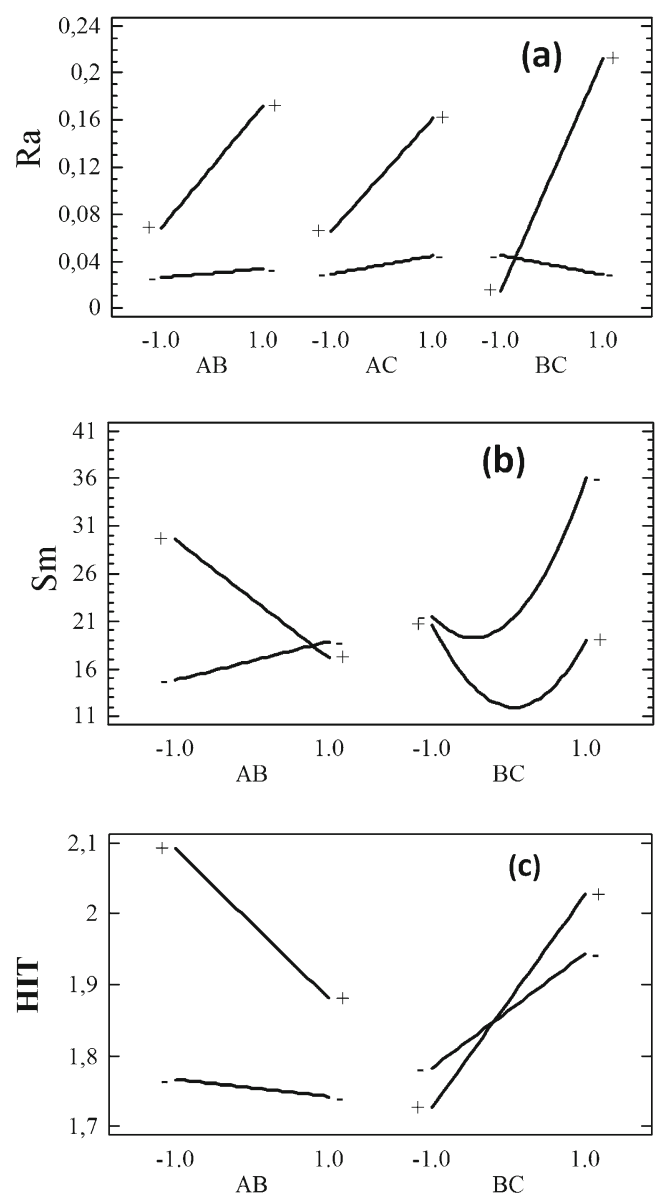

Fig. 6 Ball-burnishing interaction factors plots: a average roughness $R a$, $\mathbf{b}$ the mean spacing of profile irregularities $\mathrm{Sm}$, and $\mathbf{c}$ the micro-hardness $H v$

decrease in the recovery rate which is linked to the increase in lateral feed $f$.

In this case, we could realize the source of the existing interaction between these two factors, $\mathrm{b}_{23} a_{b} f$ term, highly and statistically significant $\left(P<10^{-4}\right)$ at a confidence level of $95 \%$ as shown in Table 6 and Fig. 6 a.

\subsubsection{Ball-burnishing factor effects on the mean spacing of profile irregularities $\mathrm{Sm}$}

The purpose of studying the mean spacing of profile irregularities $S m$ is the determination of the appropriate combination of ball-burnishing factors allowing us the minimization of this greatness and guarantees the lowest roughness profile spacing that can be achieved by applying this process in order to improve tribological behavior of treated surfaces.

Figure 5b shows that only the ball-burnishing speed factor $V_{b}$ has a linear effect on the evolution of the mean spacing of profile irregularities $S m$; on the other side penetration, depth $a_{b}$ and lateral feed $f$ have a quadratic effect. This is confirmed in the response surfaces plots shown in Fig. 9.
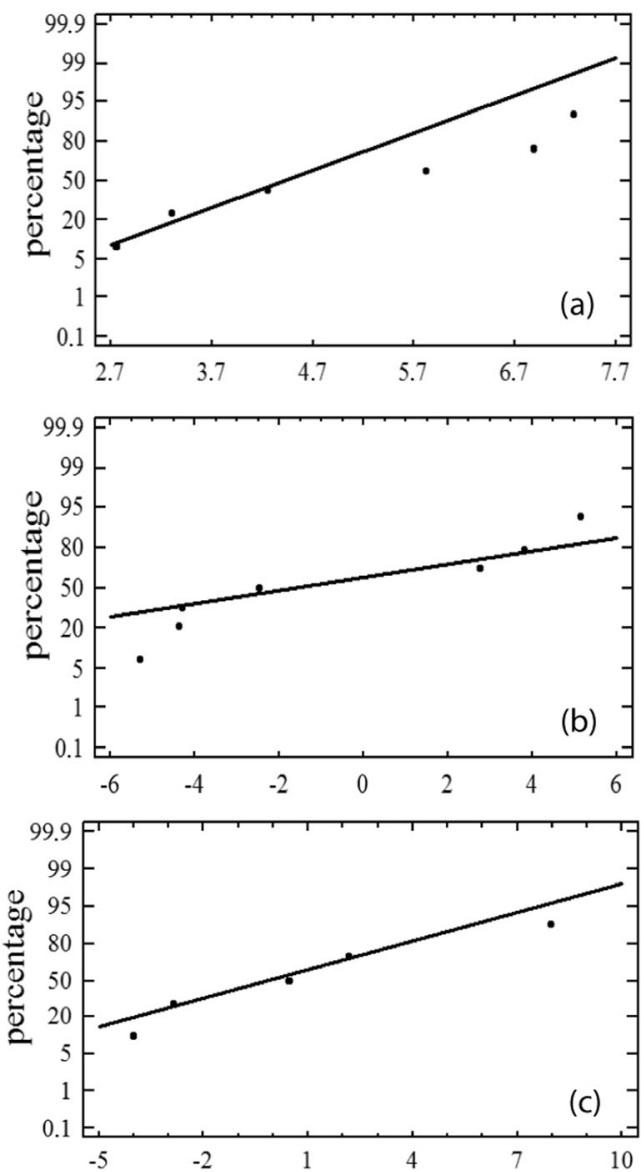

Fig. 7 Normal probability plots for residual: a average roughness $R a, \mathbf{b}$ the mean spacing of profile irregularities $S m$, and $\mathbf{c}$ the nano-hardness HIT

Table 6 and Fig. $6 \mathrm{~b}$ show the existence of two important interactions between the process factors such as $\left(V_{b}-a_{b}\right)$ having a $P$ value $=0.0015<0.05$ and another $\left(a_{b}-f\right)$ having a $P$ value $=0.0017<0.05$. Both of them influence the evolution of the roughness parameter $\mathrm{Sm}$. They are highly significant at a confidence level of $95 \%$.

For a fixed lateral feed $f=0.2 \mathrm{~mm}$ and by the variation of both ball-burnishing speed $V_{b}$ and the penetration depth $a_{b}$ in the fields established in this study, we observe an important improvement in the mean spacing of profile irregularities $\mathrm{Sm}$. So, Sm-machined surface of $35.48 \mu \mathrm{m}$, measured in the $\mathrm{X}$ direction, has been reduced to a value ranging between 10 and $30 \mu \mathrm{m}$ after ball-burnishing treatment. That is to say, a gain in $S m$ roughness parameter ranges from 66.18 to $71.81 \%$. Furthermore, response surface observation Fig. 9a shows that the best or the smallest mean spacing of profile irregularities $\mathrm{Sm}$ is given at the zero level of the penetration depth $a_{b}(10 \mu \mathrm{m} \leq S m \leq 12 \mu \mathrm{m})$.

We observe, in Fig. 9b, the linear effect of ball-burnishing speed $V_{b}$ on $S m$ parameter roughness evolution in combination with the quadratic effect of lateral feed $f$ for a given penetration depth $a_{b}$ about $40 \mu \mathrm{m}$. 
Fig. 8 Effect of ball-burnishing factor on average roughness $R a$ : a $R a=\mathrm{f}\left(V_{b}, a_{b}\right), \mathbf{b} R a=\mathrm{f}\left(V_{b}, f\right)$, and $\mathbf{c} R a=\mathrm{f}\left(a_{b}, f\right)$

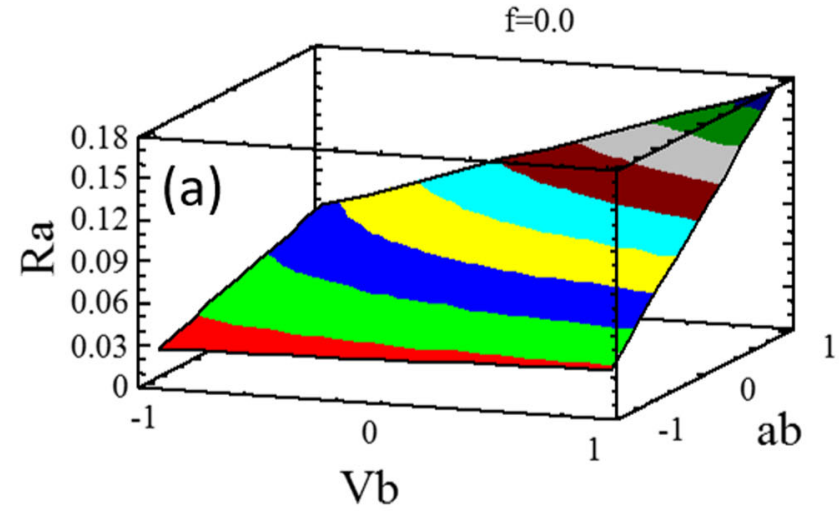

$\mathrm{f}=0.0$

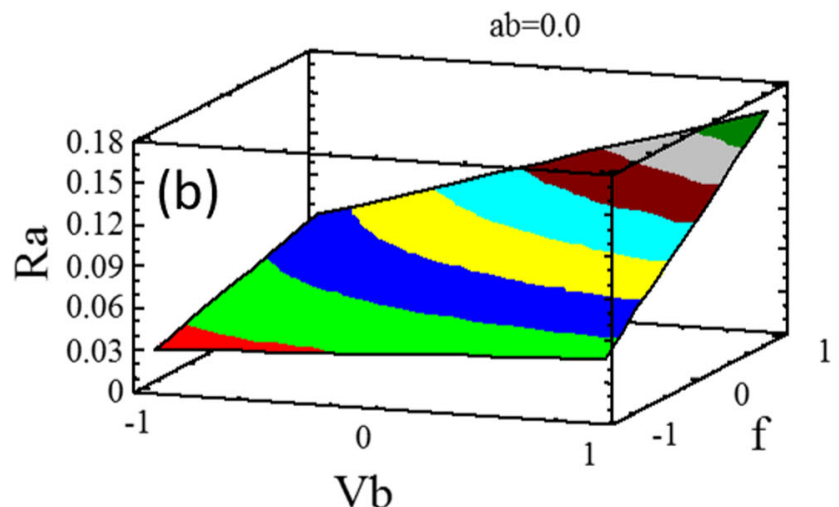

$0.0-0.018$

$0.018-0.036$

0.036-0.054

0.054-0.072

0.072-0.09

$0.09-0.108$

$0.108-0.126$

$0.126-0.144$

$0.144-0.162$

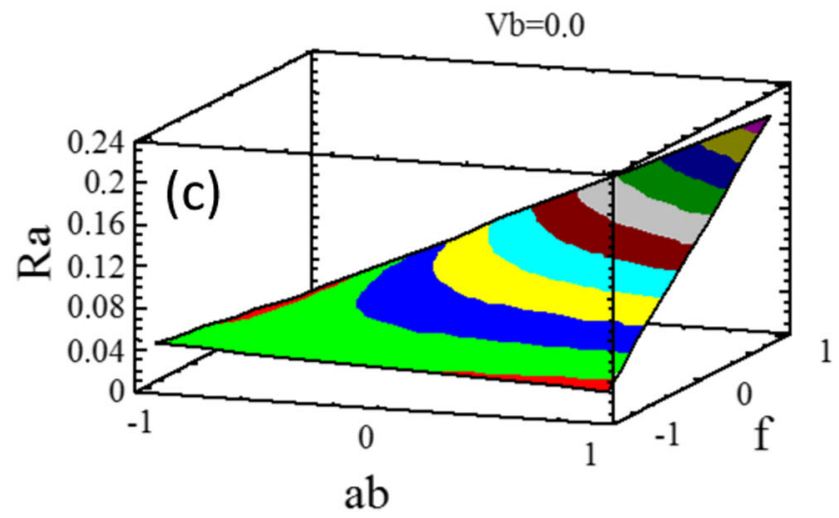

$0.0-0.018$

0.018-0.036

0.036-0.054

0.054-0.072

$0.072-0.09$

$0.09-0.108$

$0.108-0.126$

0.126-0.144

0.144-0.162

$0.162-0.18$

$0.18-0.198$

$0.198-0.216$

Figure $9 \mathrm{c}$ show the combined quadratic effect of both penetration depth $a_{b}$ and lateral feed $f$ on the mean spacing of profile irregularities $S m$ evolution for a given ball-burnishing speed $V_{b}=500 \mathrm{~mm} / \mathrm{min}$. In addition, the existence of a strong interaction $\left(a_{b}-f\right)(P$ value $=0.0017)$ significant at a confidence level of $95 \%$ explains the great potential of the two factors combination on $\mathrm{Sm}$ parameter roughness improvement, to be reduced from $35.48 \mu \mathrm{m}$ (machined surface) to a value ranging between 10 and $32 \mu \mathrm{m}$ after ball-burnishing treatment.

In this case, as shown in latter response surface plot, ballburnishing process is able to reduce the machining mean spacing of profile irregularities $S m$ from $35.48 \mu \mathrm{m}$ to a value ranging between 10 and $24 \mu \mathrm{m}$.

\subsubsection{Ball-burnishing factor effects on the nano-hardness HIT}

In this study, the surface nano-hardness improvement of machined flat surface $(1.6 \mathrm{GPa})$ is ranging between 1.7 and $2.1 \mathrm{GPa}$ after the ball-burnishing treatment; that is to say, a gain in the surface nano-hardness ranging between 6.25 and $31.25 \%$ was achieved.

Response surface $H I T=\mathrm{f}\left(V_{b}, a_{b}\right)$, Fig. 10a, shows that for low ball-burnishing speed and high penetration depth, a high surface nano-hardness ranging between 2.06 and $2.10 \mathrm{GPa}$ was achieved.

By increasing the ball-burnishing speed, a decrease in the surface nano-hardness was noticed. This explains the existing interaction between the two factors translated in nano- 

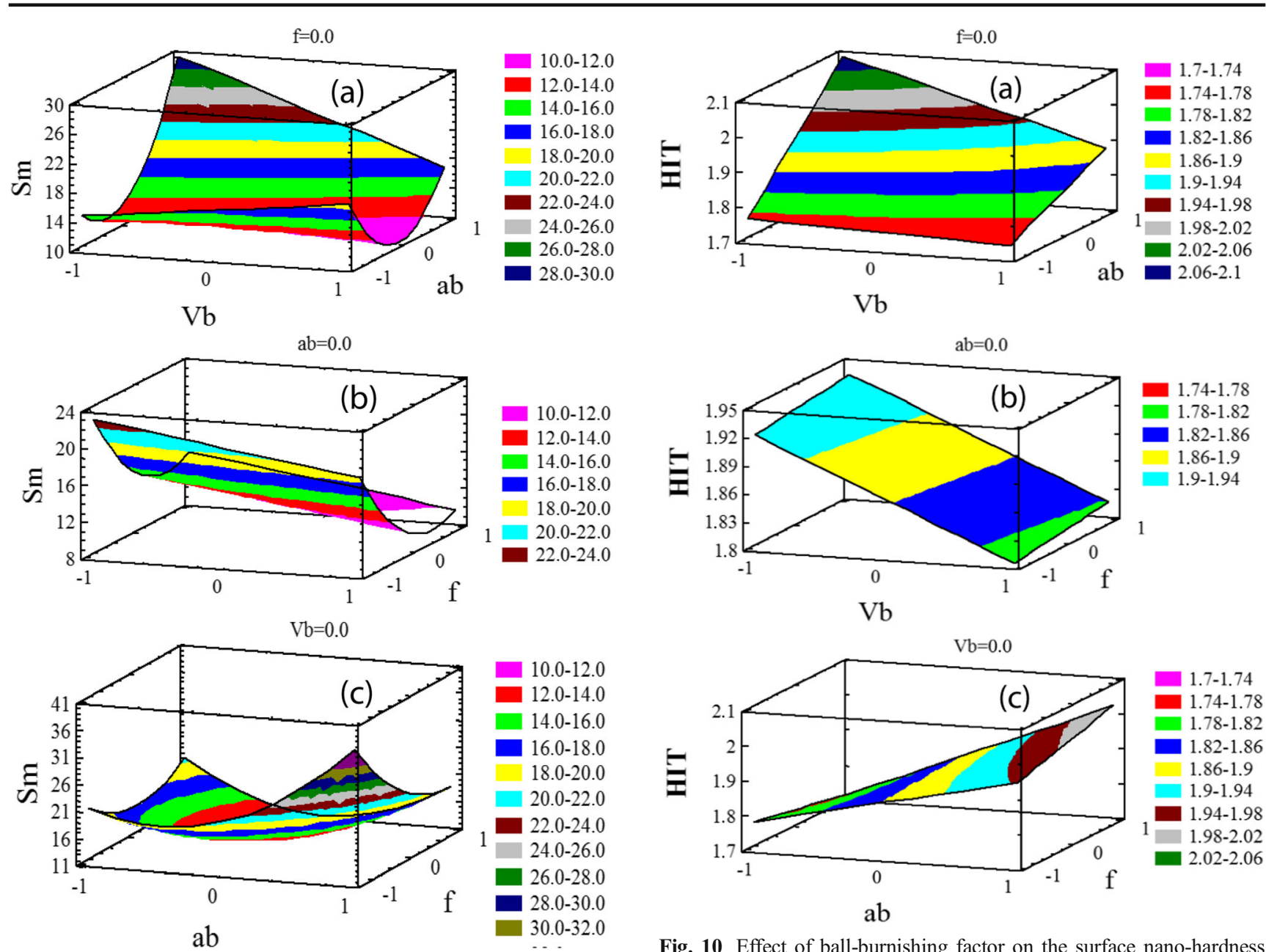

Fig. 10 Effect of ball-burnishing factor on the surface nano-hardness $H I T: \mathbf{a} H I T=\mathrm{f}\left(V_{b}, a_{b}\right), \mathbf{b} H I T=\mathrm{f}\left(V_{b}, f\right)$, and $\mathbf{c} H I T=\mathrm{f}\left(a_{b}, f\right)$

Fig. 9 Effect of ball-burnishing factor on the mean spacing of profile irregularities $S m$ : a $S m=\mathrm{f}\left(V_{b}, a_{b}\right), \mathbf{b} S m=\mathrm{f}\left(V_{b}, f\right)$, and $\mathbf{c} S m=\mathrm{f}\left(a_{b}, f\right)$

hardness model by $\mathrm{b}_{12} V_{b} a_{b}$ term which is statistically significant $(P$ value $=0.0145<0.05)$ at a confidence level of $95 \%$.

As against for a low penetration depth, the variation of the ball-burnishing speed has no influence on the nano-hardness of treated surfaces. This is due to the fact that surface nano-hardness depends mainly on the magnitude of penetration depth $a_{b}$ which is statistically significant $\left(P\right.$ value $\left.=0.05<<<10^{-4}\right)$ at a confidence level of $99 \%$, whereas the ball-burnishing speed is so $(P$ value $=0.0017<0.05)$ at a confidence level $95 \%$ as shown in Table 6 and Fig. 5c.

The low ball-burnishing speed promotes the surface hardening. So there will be a required time for the surface matter flow. In addition, the hardening level depends on the magnitude of penetration depth. However, the increase on the rise of the ball-burnishing speed has led to the hardening of the surface within less time. Then, a surface chipping was promoted by superficial micro crack formation. Consequently, a decrease of the nano-hardness surface took place whereas the roughness went up and the surface deteriorated as well. that the lateral feed $f$ is not statistically significant ( $P$ value $=0.6568>0.05$ ) Table 6 , and only the linear effect of the ball-burnishing speed is distinguishable for a given depth of penetration. As we have previously explained, the low ballburnishing speed promotes the plastic flow of material surface and, then, allows the improvement of the surface nanohardness.

Although the lateral feed $f$ is not statistically significant, the response surface $H I T=\mathrm{f}\left(a_{b}, f\right)$ Fig. 10c shows the importance of the interaction between these two factors. The latter, as shown in Table 6 , is the effect of $\mathrm{b}_{23} a_{b} f$ term which is statistically significant $(P$ value $=0.054)$ at a confidence level of $95 \%$.

An increase of the penetration depth and lateral feed for a given ball-burnishing speed tends to destroy the surface quality by increasing the surface nano-hardness and its average roughness. In this case, the material of roughness peaks strongly crushed and plastically deformed. They were repressed to left and right of the ball path rather than sealed the surface roughness valley. 


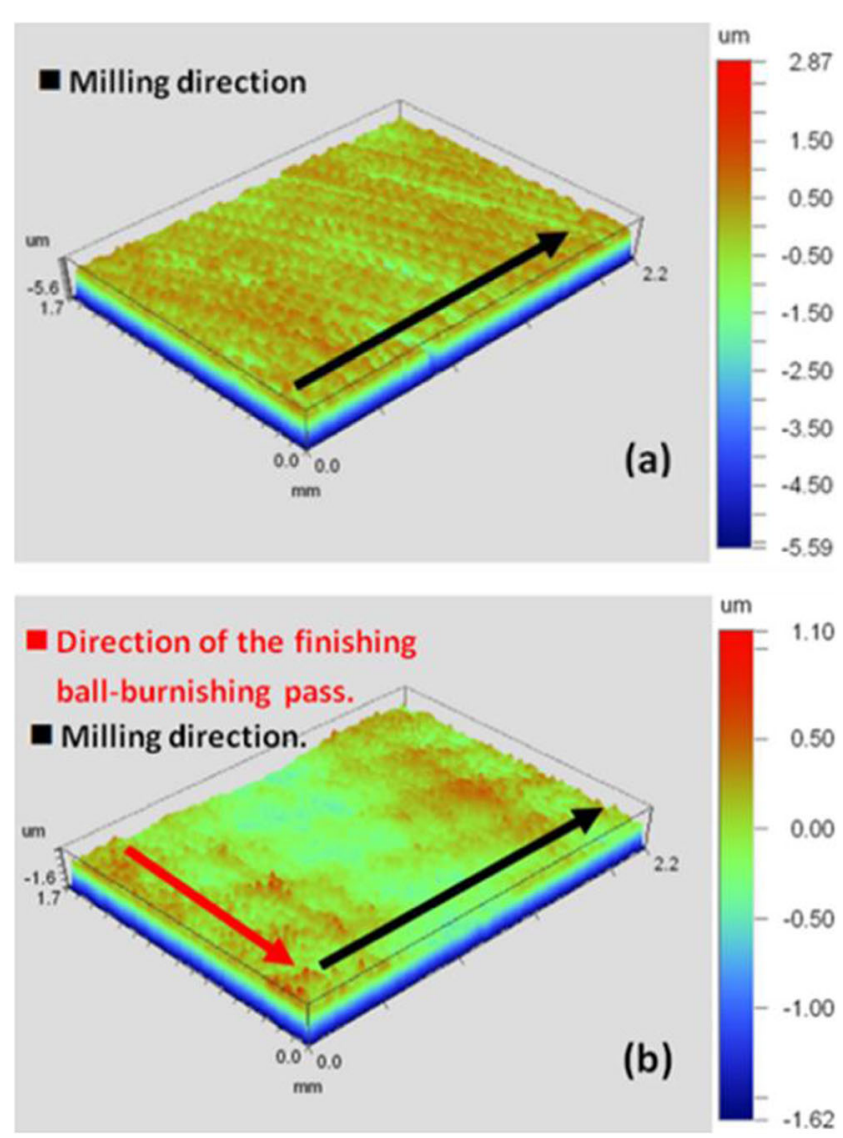

Fig. 11 Tridimensional optical roughness plot: a machined surface and b optimized ball-burnished surface

\section{Ball-burnished optimized surface}

The ball-burnishing process and modeling of machined aluminum alloy 2017A-T451 flat surfaces by the response surface methodology RSM was established in the actual study. Therefore, the potential and power of this mechanically finished treatment of machined surfaces on the enhancement of the surface integrity managed by the studied process factors are under control. A multi-objective optimization is, then,

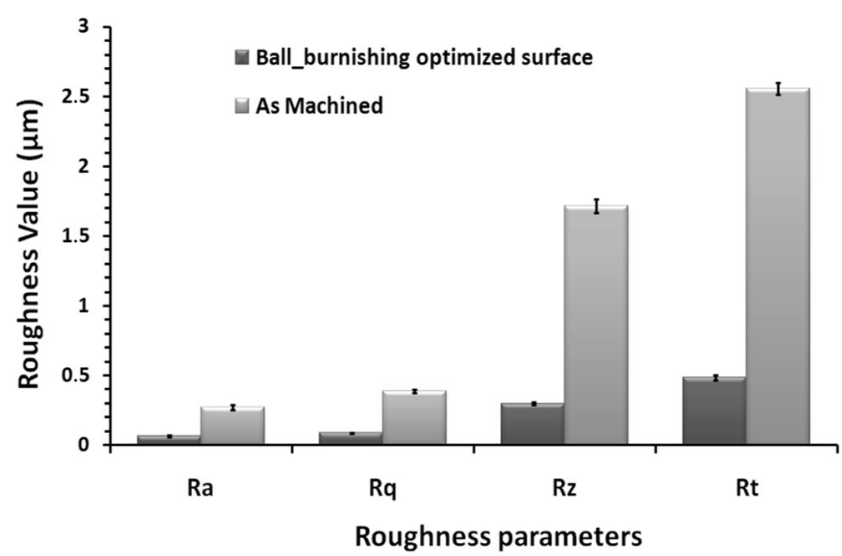

Fig. 13 Roughness enhancement with the ball-burnished optimized surface

required to determine the appropriate levels of process factors to obtain the best ball-burnished flat surface integrity.

This multi-objective optimization has the following goals:

$\left\{\begin{array}{c}\text { Minimise } \operatorname{Ra}(\mu \mathrm{m}) \\ \text { Minimise } \operatorname{Sm}(\mu \mathrm{m}) \\ \text { Maximise HIT }(\mathrm{GPa})\end{array}\right.$ For $\left\{\begin{array}{c}200 \mathrm{~mm} / \mathrm{min} \leq \mathrm{V}_{\mathrm{b}} \leq 800 \mathrm{~mm} / \mathrm{min} \\ 20 \mu \mathrm{m} \leq \mathrm{a}_{\mathrm{b}} \leq 60 \mu \mathrm{m} \\ 0.1 \mathrm{~mm} \leq f \leq 0.3 \mathrm{~mm}\end{array}\right.$

For the multi-objective optimization previous data, levels of ball-burnishing factors solution of this problem are $(0,0,0)$. That is to say, the best ball-burnished flat surface integrity in this study is provided by the following factor levels: $\left(V_{b}=500 \mathrm{~mm} / \mathrm{min}, a_{b}=40\right.$, and $\left.f=0.2 \mathrm{~mm}\right)$. The ballburnished surfaces that fit the combination of these factors' level are the four center points of the face-centered composite design listed 9, 10, 11, and 12 as shown in Table 5 and Fig. 2.

Optical three-dimensional surface roughness plots of the machined surface, Fig. 11a, and that of the ball-burnished optimized surface, Fig. 11b, show clearly the contribution of this ball-burnishing process by crushing the roughness peaks and pushing them in valleys. This is beneficial to block and minimize the future potential priming sites' cracks which are the roughness valleys of the machined surface.
Fig. 12 Comparison

bidirectional roughness profiles of machined surface and optimized ball-burnished one

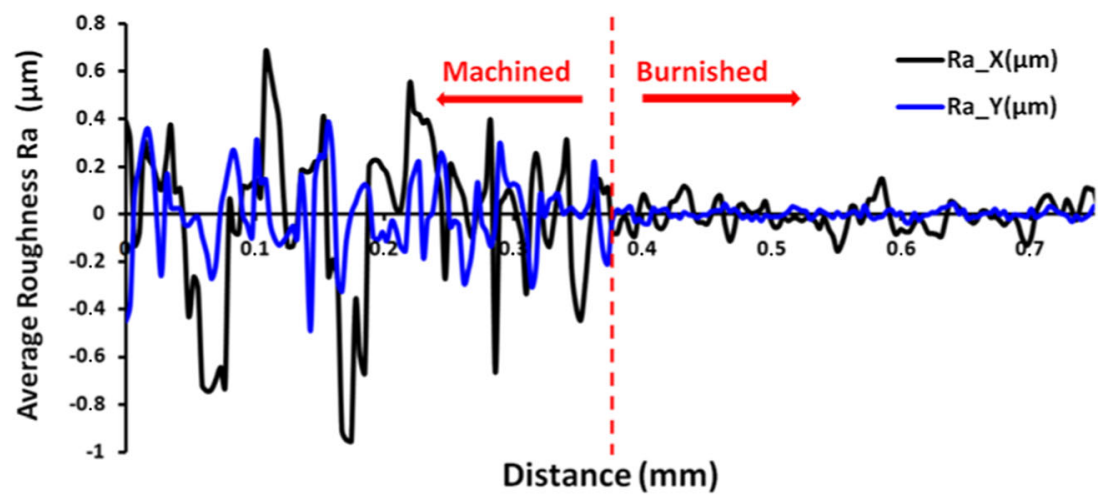




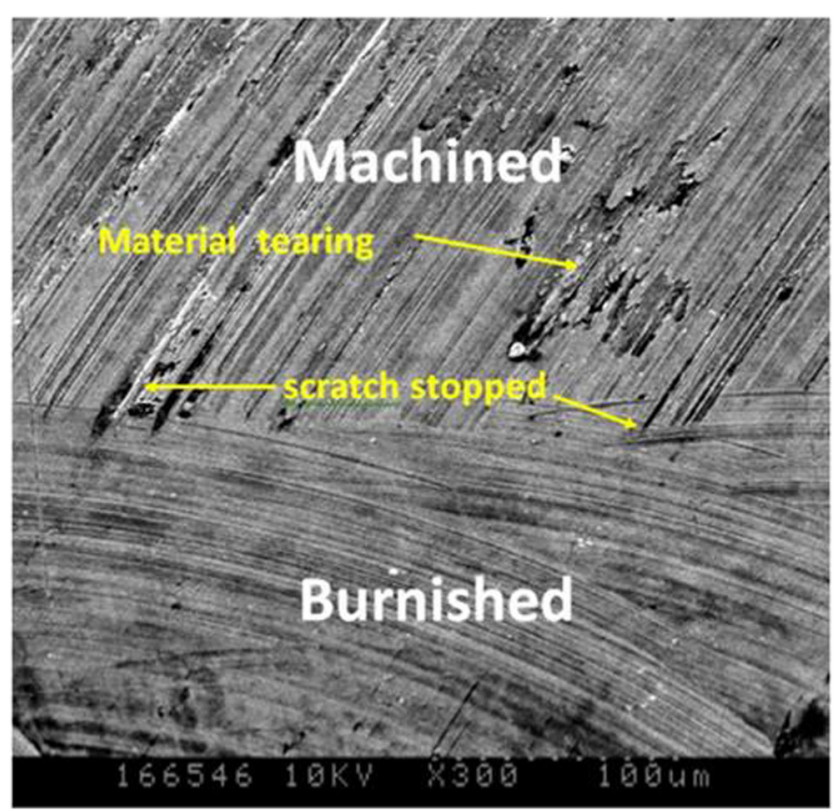

Fig. 14 SEM micrograph of the transition area between the optimized ball-burnished surface and the machined surface

In addition, the comparison roughness profiles, according to the machining direction ( $X$-axis), to that of the finishing ball-burnishing pass ( $Y$-axis), Fig. 12, shows that surface quality is better along the $Y$-axis for the two surfaces. Then, the high machined surface roughness anisotropy is reduced and improved after ball-burnishing treatment.

Therefore, according to Fig. 13, the best qualities of the ball-burnished optimized surface for light reflection (mirrored surface), Fig. 3, have been achieved thanks to the low roughness amplitudes measured after ball-burnishing surface treatment.

Furthermore, Fig. 14 shows the great impact of the ballburnishing process to stop the surface scratching left by the cutting tool after material tearing during machining. This process is, then, able by means of a surface hardening, to erase the cutting tool traces via crushing the scales formed

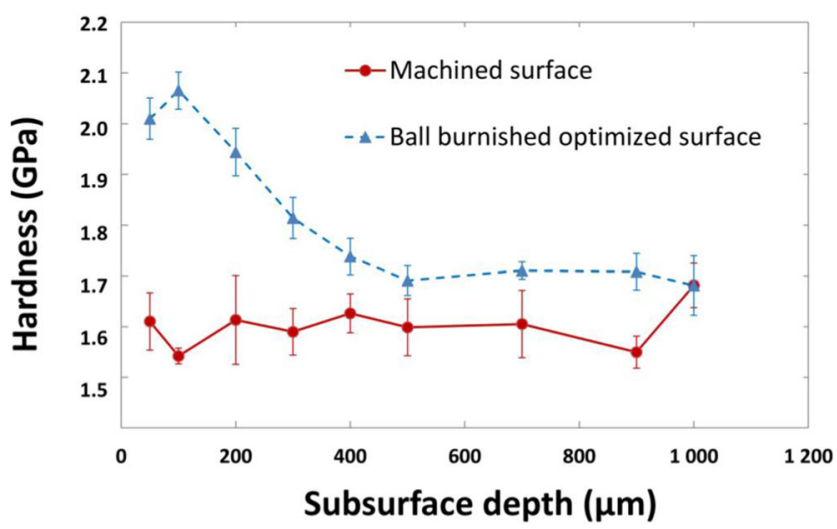

Fig. 15 Comparison of nano-hardness under layer profiles of the optimized ball-burnished surface with the machined surface during the machining process. Finally, the nano-hardness under layer, Fig. 15, shows a comparison of the evolution of nano-hardness profiles, depending on the depth of the optimized burnished surface to the machined one. We notice that the nano-hardness sub-layer has visibly enhanced not solely at the surface level but also at a depth greater or equal to $500 \mu \mathrm{m}$.

\section{Conclusion}

In this study, a ball-burnishing experimental work applied on flat surface of 2017-T451 aluminum alloy was conducted following a face-centered composite design formed by three factors at three levels. The mathematical modeling of the three most studied surface integrity parameters such as average roughness $R a$, mean spacing of profile irregularities $S m$, and surface nano-hardness HIT was successfully conducted using the response surface methodology RSM.

Using a two crossed-pass ball-burnishing strategy ZIG/ ZAG_SEUIL has led to an optimized ball-burnished surface obtained by the combination of $(0,0,0)$ levels of studied ballburnishing factors $\left(V_{b}=500 \mathrm{~mm} / \mathrm{min}, a_{b}=40\right.$, and $f=0.2 \mathrm{~mm}$ ).

Compared to the machined surface, the ball-burnished optimized surface is characterized by a gain in average roughness $R a$ of $81 \%$, an improvement in the mean spacing of profile irregularities $\mathrm{Sm}$ of $34 \%$, and an enhancement in nano-hardness surface HIT of $17 \%$.

In addition, the optimized surface shows a high ability for closing scratches formed during machining. That is to say, to minimize future potential priming site cracks.

Finally, the use of this new two crossed-pass ball-burnishing strategy shows a great power in reducing the superficial geometrical roughness irregularities of the machined surface. As a result, an enhancement of both the surface roughness and the subsurface hardness occur.

But all the ball-burnished surfaces have presented an anisotropic roughness behavior which varied from one treated surface to another depending on the applied factor levels. This measurable anisotropy is malefic for tribological behavior of ball-burnished flat surfaces and, so, should be minimized in a future optimized work.

Acknowledgments The authors are grateful to the Higher Institute of Technological Studies (ISET) KEF, Tunisia, to have supported the experimental work of milling and mechanical treatment by ball-burnishing. Special thanks also furnish to the Arts et Metiers ParisTech (ENSAM) LILLE, France, for its great participation in measurement and characterization of treated surfaces. 


\section{References}

1. Salahshoor M, Guo YB (2011) Surface integrity of biodegradable magnesium-calcium orthopedic implant by burnishing. J Mech Behav Biomed Mater 4(8):1888-904. doi:10.1016/j.proeng.2011. 11.114

2. El-Axir MH, Othman OM, Abodiena AM (2008) Study on the inner surface finishing of aluminum alloy 2014 by ball-burnishing process. Journal of materials processing technology 202:435-442. doi:10.1016/j.jmatprotec.2007.10.040

3. Bouzid W, Tsoumarev O, SaÏ K (2004) An investigation of surface roughness of burnished AISI 1042 steel. Int J Adv Manuf Technol 24:120-125. doi:10.1007/s00170-003-1761-4

4. Shiou F-J, Chen C-CA, Wen-Tu L (2006) Automated surface finishing of plastic injection mold steel with spherical grinding and ball burnishing processes. Int J Adv Manuf Technol 28:6166. doi:10.1007/s00170-004-2328-8

5. Revankar GD, Shetty R, Rao SS, Gaitonde VN (2014) Analysis of surface roughness and hardness in ball-burnishing of titanium alloy. Measurement 58:256-268. doi:10.1016/j.measurement.2014.08.043

6. López de Lacalle LN, Lamikiz A, Sánchez JA, Arana JL (2007) The effect of ball-burnishing on heat-treated steel and Inconel 718 milled surfaces. The International Journal of Advanced Manufacturing Technology 32:958-968. doi:10.1007/s00170-0050402-5

7. Akkurt A (2011) Comparison of roller burnishing and other methods of finishing treatment of the surface of openings in parts from tool steel D3 for cold forming. Metal Science and Heat Treatment 53:145-150. doi:10.1007/s11041-011-9358-2

8. Akkurt A (2011) Comparison of roller burnishing method with other hole surface finishing processes applied on AISI 304 austenitic stainless steel. JMEPEG 20:960-968. doi:10.1007/s11665-0109718-x

9. Hassan AM (1997) The effects of ball- and roller-burnishing on the surface roughness and hardness of some non-ferrous metals. Journal of Materials Processing Technology 72:385-391. doi:10. 1016/S0924-0136(97)00199-4

10. Hanus E, Ericsson T (1995) Effect of pressure rolling on the residual stress state of a particulate-reinforced metal matrix composite. Materials Science and Engineering 90:155-163. doi:10.1016/09215093(94)09565-5

11. Hassan AM, Al-Wahhab OM (1998) Surface characteristics of some roller burnished non-ferrous components. Mater Manuf Process 13(4):505-515. doi:10.1080/10426919808935272
12. Loh NH, Tam SC (1988) Effects of ball-burnishing parameters on surface finish - a literature survey and discussion. Precision Engineering 10(4):215-220. doi:10.1016/0141-6359(88)90056-6

13. Hassan AM, Maqableh AM (2000) The effects of initial burnishing parameters on non-ferrous components. Journal of Materials Processing Technology 102:115-121. doi:10.1016/S09240136(00)00464-7

14. Shiou F-J, Chen C-H (2003) Determination of optimal ballburnishing parameters for plastic injection moulding steel. Int $\mathrm{J}$ Adv Manuf Technol 21(3):177-185. doi:10.1007/s001700300019

15. El-Taweel TA, El-Axir MH (2009) Analysis and optimization of the ball burnishing process through the Taguchi technique. Int $\mathrm{J}$ Adv Manuf Technol 41:301-310. doi:10.1007/s00170-008-1485-6

16. Sarhan AAD, El-Tayeb NSM (2014) Investigating the surface quality of the burnished brass C3605 - fuzzy rule-based approach. Int J Adv Manuf Technol 71:1143-1150. doi:10.1007/s00170-0135543-3

17. Sagbas A (2011) Analysis and optimization of surface roughness in the ball-burnishing process using response surface methodology and desirability function. Advances in Engineering Software 42: 992-998. doi:10.1016/j.advengsoft.2011.05.021

18. Loh NH, Tam SC, Miyazawa S (1993) Application of experimental design in ball burnishing. Int J Mach Tools Manufact 33:841-852. doi:10.1016/0890-6955(93)90041-R

19. Loh NH, Tam SC, Miyazawa S (1990) Use of response surface methodology to optimize the finish in ball burnishing. Precision Engineering 12(2):101-105. doi:10.1016/0141-6359(90)90035-W

20. Yuan XL, Sun YW, Gao LS, Jiang SL (2015) Effect of roller burnishing process parameters on the surface roughness and microhardness for TA2 alloy. Int J Adv Manuf Technol 1-11. doi: 10. 1007/s00170-015-8031-0

21. Shiou F-J, Hsu C-C (2008) Surface finishing of hardened and tempered stainless tool steel using sequential ball grinding, ballburnishing and ball polishing processes on a machining centre. Journal of materials processing technology 205:249-258. doi:10. 1016/j.jmatprotec.2007.11.244

22. Oliver WC, Pharr GM (1992) An improved technique for determining hardness and elastic modulus using load and displacement sensing indentation experiments. J Mater Res 7:1564-1583. doi:10. 1557/JMR.1992.1564

23. Myers RH, Montgomery DC, Anderson-Cook CM (2009) Response surface methodology: process and product optimization using designed experiment, 3rd edn. Wiley, New York, pp 417434, ISBN: 978-0-470-17446-3 